\title{
Annex 7
}

\section{Ratifications of and Signatures to Key Human Rights Treaties by Commonwealth Countries in 2008}

\section{Ratifications}

International Covenant on Civil and Political Rights (ICCPR)

\begin{tabular}{lll}
\hline Country & Date of ratification & UPR session \\
\hline The Bahamas & 23 December 2008 & 3rd session (2008) \\
Papua New Guinea & 21 July 2008 & 11 th session (2011) \\
Samoa & 15 February 2008 & 11 th session (2011) \\
Vanuatu & 21 November 2008 & 5th session (2009) \\
Pakistan & 17 April 2008 & 2nd session (2008) \\
\hline
\end{tabular}

International Covenant on Economic, Social and Cultural Rights (ICESCR)

\begin{tabular}{lll}
\hline Country & Date of ratification & UPR session \\
\hline The Bahamas & 23 December 2008 & 3rd session (2008) \\
Pakistan & 17 April 2008 & 2nd session (2008) \\
Papua New Guinea & 21 July 2008 & 11 th session (2011) \\
\hline
\end{tabular}

Migrant Workers Convention (MWC)

\begin{tabular}{lll}
\hline Country & Date of ratification & UPR session \\
\hline Jamaica & 25 September 2008 & 9th session (2010) \\
\hline
\end{tabular}


Convention on the Rights of Persons with Disabilities (CRPD)

\begin{tabular}{lll}
\hline Country & Date of ratification & UPR session \\
\hline Australia & 17 July 2008 & 10th session (2011) \\
Kenya & 19 May 2008 & 8th session (2010) \\
Lesotho & 2 December 2008 & 8th session (2010) \\
Uganda & 25 September 2008 & 12th session (2011) \\
Vanuatu & 23 October 2008 & 5th session (2009) \\
Cameroon & 1 October 2008 & 4th session (2009) \\
Malaysia & 8 April 2008 & 4th session (2009) \\
\hline
\end{tabular}

\section{CRPD Optional Protocol (OP)}

\begin{tabular}{lll}
\hline Country & Date of ratification & UPR session \\
\hline Bangladesh & 12 May 2008 & 4th session (2009) \\
Uganda & 25 September 2008 & 12th session (2011) \\
Cameroon & 1 October 2008 & 4th session (2009) \\
Tanzania & 29 September 2008 & 12th session (2011) \\
Zambia & 29 September 2008 & 2nd session (2008) \\
\hline
\end{tabular}

Convention on the Elimination of all Forms of Discrimination Against Women (CEDAW), Optional Protocol

\begin{tabular}{lll}
\hline Country & Date of ratification & UPR session \\
\hline Australia & 4 December 2008 & 10th session (2011) \\
\hline
\end{tabular}

Convention on the Rights of the Child (CRC), Optional Protocol I (Children in Armed Conflict)

\begin{tabular}{lll}
\hline Country & Date of ratification & UPR session \\
\hline Singapore & 11 December 2008 & 11th session (2011) \\
\hline
\end{tabular}




\section{Signatures}

\section{Convention Against Torture (CAT)}

\begin{tabular}{lll}
\hline Country & Date of signature & UPR session \\
\hline The Bahamas & 16 December 2008 & 3rd session (2008) \\
Pakistan & 17 April 2008 & 2nd session (2008) \\
\hline
\end{tabular}

Convention on the Rights of the Child (CRC), Optional Protocol I (Children in Armed Conflict)

\begin{tabular}{lll}
\hline Country & Date of signature & UPR session \\
\hline Cyprus & 1 July 2008 & 6th session (2009) \\
Pakistan & 25 September 2008 & 2nd session (2008) \\
Solomon Islands & 23 September 2008 & 11 th session (2011) \\
Zambia & 9 May 2008 & 2nd session (2008) \\
\hline
\end{tabular}

Convention on the Rights of the Child, Optional Protocol II (Sale of children, child prostitution and child pornography)

\begin{tabular}{lll}
\hline Country & Date of signature & UPR session \\
\hline Zambia & 29 September 2008 & 2nd session (2008) \\
\hline
\end{tabular}

